Cite this: Chem. Commun., 2014, 50, 3579

Received 17th December 2013, Accepted 7th February 2014

DOI: $10.1039 / c 3 c c 49555 h$

www.rsc.org/chemcomm

\section{Turn-on fluorescent probes for nitric oxide sensing based on the ortho-hydroxyamino structure showing no interference with dehydroascorbic acid $\dagger$}

\author{
Alicia Beltrán, ${ }^{a}$ M. Isabel Burguete, ${ }^{a}$ Daniel R. Abánades, ${ }^{b}$ Dolores Pérez-Sala, ${ }^{b}$ \\ Santiago V. Luis ${ }^{* a}$ and Francisco Galindo*a
}

A new family of fluorescent synthetic molecular probes for nitric oxide sensing based on ortho-hydroxyamino-triarylpyrylium salts is presented.

Nitric oxide (NO) has captured the attention of many researchers during the last decade. Interest in NO derives from its known biological activity, in particular its pivotal role in vasodilatation or its functions as a neurotransmitter and an antimicrobial agent. ${ }^{1}$

Fluorescence techniques have become very popular for NO sensing because of their high sensitivity and spatiotemporal resolution when combined with microscopy. ${ }^{2}$ Thus, the construction of small fluorescent sensors suitable for specific NO detection in living systems has received great attention. A number of fluorescent probes have been reported to date. The most common approach for NO detection involves the use of $o$-diamino aromatics under aerobic conditions. These molecules react with $\mathrm{N}_{2} \mathrm{O}_{3}$ (formed from $\mathrm{NO}$ and $\mathrm{O}_{2}$ ), to yield fluorescent triazole derivatives. ${ }^{3}$

Another family of probes, in this case reacting directly with NO, is based on transition-metal complexes. ${ }^{4}$ An increasing number of other strategies have been described in the literature. ${ }^{5}$

Furthermore, although the past several years have witnessed great progress in the development of ortho-diamine fluorescent probes, they still have some shortcomings. One of the most important drawbacks, is that dehydroascorbic acid (DHA) reacts with $o$-diamino aromatics and turns on the fluorescence of such probes in an analogous way as $\mathrm{N}_{2} \mathrm{O}_{3}$ does. As pointed out by Sweedler and coworkers, dehydroascorbic acid reacts with ortho-diamine probes to give fluorescent adducts which are indistinguishable from those arising from the reaction with $\mathrm{N}_{2} \mathrm{O}_{3}{ }^{6}$ To solve this problem various correction strategies have been developed, including freezing of the

\footnotetext{
${ }^{a}$ Universitat Jaume I, Departamento de Química Inorgánica y Orgánica, Avda. Sos Baynat s/n, 12071, Castellón, Spain. E-mail: francisco.galindo@uji.es, luiss@uji.es ${ }^{b}$ Centro de Investigaciones Biológicas, C.S.I.C., Ramiro de Maeztu, 9, 28040 Madrid, Spain

$\dagger$ Electronic supplementary information (ESI) available: Synthetic procedures and characterizations, fluorometric and absorption studies, and X-ray crystallographic and biological studies. CCDC 977073-977075. For ESI and crystallographic data in CIF or other electronic format see DOI: 10.1039/c3cc49555h
}

medium, ${ }^{7}$ using enzymes and capillary electrophoresis ${ }^{8}$ and multiderivatization image analysis. ${ }^{9}$ In this regard, notable detection limits have been reached using a contactless correction method $(10 \mathrm{nM}) .^{7}$ It should be noted that not taking into account this important biological interfering species may lead researchers in biomedical areas to wrongly interpret the recorded data. However, developing a more selective probe, not reactive with DHA, thus avoiding the aforementioned correction methods, continues to be an important target of current interest in the field.

Herein we present the development of a new family of synthetic molecular probes for NO in an oxygenated medium based on the pyrylium cation which meets the essential criteria, namely: (1) they are sensitive to $\mathrm{NO} / \mathrm{O}_{2}$ without showing significant interference with other reactive nitrogen (RNS) and oxygen species (ROS), and especially without showing interference with dehydroascorbic acid, and (2) they are obtained by a simple methodology that allows efficient synthesis of the product in only two synthetic steps and in high yields from readily available starting products. Besides, the synthetic procedure allows for a straightforward introduction of structural variants favoring a fine tuning of the different spectroscopic properties (excitation and fluorescence emission wavelengths, emission quantum yields, and fluorescence lifetimes, etc.).

The key factor to accomplish the above-mentioned features is the utilization of the ortho-hydroxyamino structure instead of the traditional ortho-diamino one.

The synthesis of compounds $2 \mathbf{a}-\mathbf{d}$ started with the preparation of the intermediates 1a-d with an ortho-hydroxynitro substructure (Fig. 1). Intermediates $\mathbf{1 a - d}$ were easily prepared by adding $\mathrm{BF}_{3}$. $\mathrm{OEt}_{2}$ to a solution of 4-hydroxy-3-nitrobenzaldehyde and the corresponding acetophenone in anhydrous toluene. The solution was refluxed for $2 \mathrm{~h}$. After cooling to room temperature, acetone was added and the solution was poured into excess ether. A precipitate was formed which was then filtered, washed with ether and dried under vacuum. A series of analyses confirmed that the precipitate was the hydroxynitro pyrylium salts 1a-d. Compounds 2a-d were obtained by reduction of the nitro group to an amino group by using $\mathrm{SnCl}_{2} \cdot 2 \mathrm{H}_{2} \mathrm{O}$ in dichloromethane and excess of hydrochloric acid under nitrogen atmosphere. The reaction mixture was refluxed for 


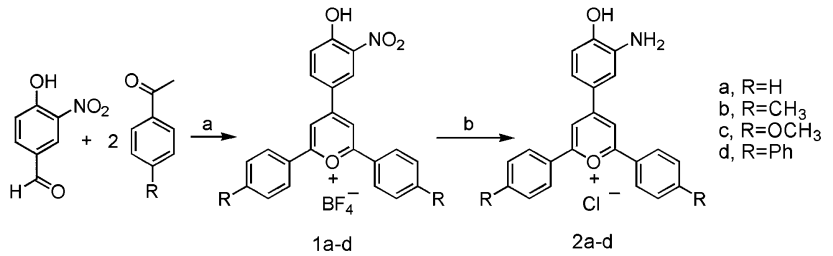

Fig. 1 Synthesis of the pyrylium probes 2. Reagents and conditions: (a) $\mathrm{BF}_{3} \cdot \mathrm{OEt}_{2}$ in toluene (2 $\mathrm{h}$, reflux) and (b) $\mathrm{SnCl}_{2} \cdot \mathrm{H}_{2} \mathrm{O}, \mathrm{HCl}$ in $\mathrm{CH}_{2} \mathrm{Cl}_{2}(3 \mathrm{~h}$, reflux).

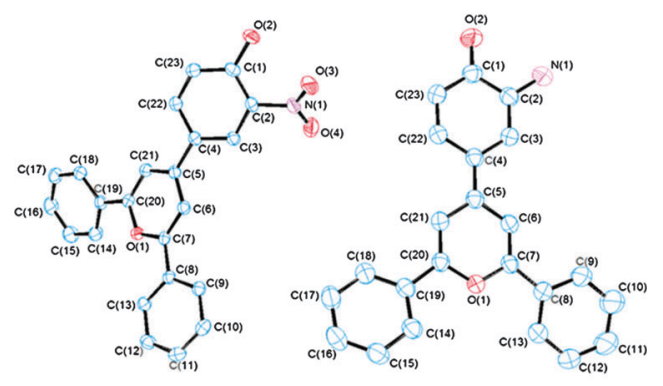

$1 \mathrm{a}$

$2 a$

Fig. 2 X-ray structures of compounds $1 \mathbf{a}$ and $2 \mathbf{a}$.

$3 \mathrm{~h}$ and extracted with dichloromethane. Analyses of the purified products by HRMS, ${ }^{1} \mathrm{H}$ NMR and ${ }^{13} \mathrm{C}$ NMR spectroscopy confirmed the identity of 2a-d. Furthermore, for compounds 1a and 2a crystals suitable for X-ray diffraction were obtained (Fig. 2). As it can be seen, the keto (deprotonated) form of $2 \mathbf{a}$ is obtained in the solid state. ${ }^{10}$

All pyrylium salts 2a-d were sensitive to the presence of an excess of NO in aerated water, their absorption spectra changing dramatically after bubbling gaseous NO. Besides, compound 2c displayed a remarkable fluorescence turn-on response with a 83-fold increase in the intensity of the fluorescence signal relative to 1c, excited under the same conditions, (Fig. 3). Photophysical properties of compounds $2 \mathbf{a}-\mathbf{d}$ and reaction products of $2 \mathbf{a}-\mathbf{d}$ with $\mathrm{NO} / \mathrm{O}_{2}$ are summarized in Table 1.

The corresponding analytical limits of detection (LOD) for $\mathbf{2 a - d}$ were calculated according to the IUPAC method (blank $+3 \sigma),{ }^{11}$ and are presented in Table 2. As can be seen in Table 2, the LOD for $2 \mathbf{c}$ is $2.1 \mu \mathrm{M}$ whereas the LOD for the rest of the probes are higher. As micromolar concentrations of NO are typically formed in cultures of macrophages ${ }^{1}$ for instance, the obtained LOD values suggest that our probes could be useful for measurements in these cell types. Besides, a good linear correlation $\left(R^{2}=0.995\right)$ between the fluorescence intensity and the NO concentration was also found for compound 2c.

As stated above, the high specificity of the probe is imperative for its application. In this regard, we screened a wide array of possible competitive RNS and ROS plus other species (50 equivalents): $\mathrm{H}_{2} \mathrm{O}_{2}$, $\mathrm{ClO}^{-}, \mathrm{O}_{2}{ }^{-},{ }^{\bullet} \mathrm{OH},{ }^{1} \mathrm{O}_{2}, \mathrm{NO}_{3}{ }^{-}, \mathrm{NO}_{2}{ }^{-}, \mathrm{ONOO}^{-}, \mathrm{HNO}$, ascorbic acid (HAA) and dehydroascorbic acid (DHA). As shown in Fig. 3, no detectable responses for these reagents were observed under the same conditions. Moreover, DHA was found not to diminish the sensitivity of $2 \mathrm{c}$ towards NO (Fig. S15, ESI $\dagger$ ).

In order to get deeper knowledge about the mechanism involved in the fluorescence turn-on response of compounds
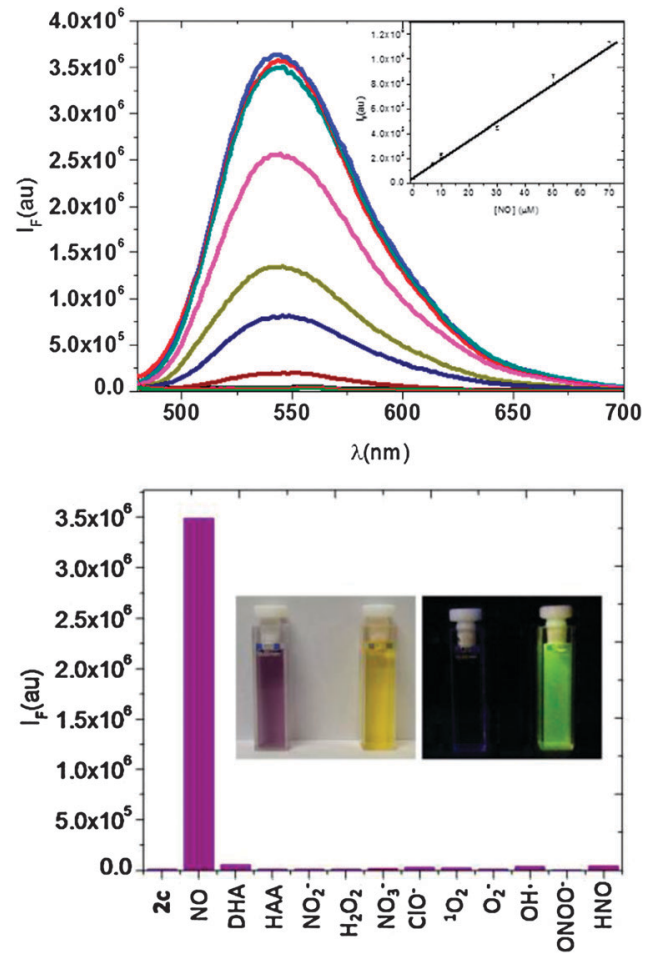

Fig. 3 Spectroscopic studies using $2 \mathrm{c}$ as a probe for NO. On the top: emission spectra of compound $\mathbf{2 c}(10 \mu \mathrm{M})$ in aerated water at $\mathrm{pH} 7.2$ in the presence of increasing amounts of $\mathrm{NO}$ (from $0.1 \mu \mathrm{M}$ to $1000 \mu \mathrm{M}),\left(\lambda_{\text {exc }}=\right.$ $470 \mathrm{~nm})$. On the bottom: emission intensity at $\lambda=550 \mathrm{~nm}$ of compound 2c $(10 \mu \mathrm{M})$ in aerated water at $\mathrm{pH} 7.2$ in the presence of NO, other RNS/ ROS and DHA/HAA (50 equiv.). Also shown photographs of solutions of $\mathbf{2 c}$ before and after exposure to NO (under visible and UV light).

Table 1 Photophysical properties of compounds $\mathbf{2 a - d}$

\begin{tabular}{llll}
\hline & Compound & $\lambda_{\text {abs }}(\mathrm{nm})(\log \varepsilon)$ & $\lambda_{\text {emis }}(\mathrm{nm})$ \\
\hline 2a & Before NO & $365(4.0), 549(4.2)$ & 475 \\
& After NO & $418(4.0)$ & 484 \\
2b & Before NO & $379(3.6), 550(3.6)$ & 485 \\
& After NO & $430(3.9)$ & 503 \\
2c & Before NO & $407(3.8), 550(3.8)$ & 527 \\
& After NO & $465(3.8)$ & 543 \\
2d & Before NO & $411(3.6), 540(3.6)$ & 480 \\
& After NO & $433(3.2)$ & 523
\end{tabular}

Table 2 Limits of detection (LOD) for compounds $\mathbf{2}(\mathbf{a}-\mathrm{d}$ ) towards NO (aerated aqueous solution)

\begin{tabular}{lcc}
\hline Compound & Enhancement factor & LOD $(\mu \mathrm{M})$ \\
\hline 2a & 8 & 12.2 \\
2b & 31 & 6.3 \\
2c & 83 & 2.1 \\
2d & 5 & 46.7
\end{tabular}

$\mathbf{2 a - d}$ in the presence of NO/air, a sample of $2 \mathbf{a}$ was allowed to react with an excess of NO in aerated water and the isolated product was analyzed by ${ }^{1} \mathrm{H}$ NMR, ${ }^{13} \mathrm{C}$ NMR, HRMS and FTIR spectroscopy. Surprisingly, no product was found to have an increased molecular weight other than one with $M^{+}=325$, 12133, suggesting that the reaction with $\mathrm{N}_{2} \mathrm{O}_{3}$ leads to 

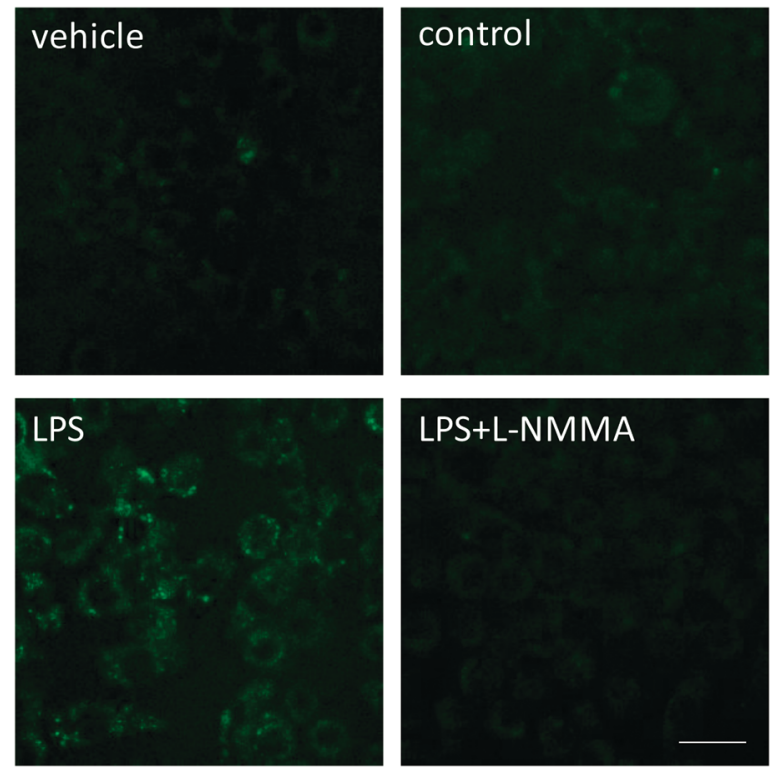

Fig. 4 Fluorescence of probe 2 c in murine macrophages. RAW264.7 cells were cultured in the presence of the indicated agents. After incubation with the $2 \mathrm{c}$ probe at $37{ }^{\circ} \mathrm{C}$ for $30 \mathrm{~min}$, cells were visualized by confocal microscopy. Scale bar: $20 \mu \mathrm{m}$.

deamination of the probe. ${ }^{12}$ As a matter of fact, crystals of the reaction product suitable for X-ray diffraction were obtained, confirming the loss of the amine group (Fig. S19, ESI $\dagger$ shows the deaminated product, also in the keto form after loss of a proton from the hydroxy group). The presence of a hydroxy group neighboring the amine functionality must be the key factor for this reaction to occur. In order to confirm this hypothesis, model compound 4, bearing only $\mathrm{NH}_{2}$, was synthesized and tested towards $\mathrm{NO} / \mathrm{O}_{2}$ and no fluorescence enhancement was recorded.

We have also assessed the ability of compound $2 \mathrm{c}$ for imaging NO in live macrophages (RAW264.7) by means of confocal fluorescence microscopy. Cells incubated in the presence of a vehicle showed negligible fluorescence. Non-activated macrophages incubated with the probe showed a weak background. Macrophages (activated with LPS and IFN- $\gamma$ to produce NO) showed a clear increase in fluorescence with a predominantly cytosolic distribution (Fig. 4). This increase was blunted when cells were activated in the presence of the NOS inhibitor L-NMMA. As a control for these assays, the accumulation of nitrite in the cell supernatants was measured, reflecting the increase in NO generation upon macrophage activation, which was reduced by $50 \%$ in the presence of L-NMMA (Fig. S20, ESI $\dagger$ ). Taken together, these results suggest that the increase in fluorescence observed in activated cells is due to NOS-generated NO. ${ }^{13}$ It is worth noting that under these conditions only intracellular fluorescence was detected.

In summary, we have developed a new family of probes, based on pyrylium salts and the ortho-hydroxyamino structure, which are sensitive to NO (aerated solution). Deamination of the probe takes place leading to a highly fluorescent product. The new probes are sensitive to NO at the micromolar level, present no interference with DHA and are suitable for the imaging of NO in live RAW264.7 cells by confocal microscopy.
Work at UJI was financially supported by the MINECO (CTQ2009-09953, CTQ2012-38543-C03-01), GV (PROMETEO/ 2012/020) and UJI (P1 1B-2012-41). A.B. is grateful for the support of a FPU fellowship. Technical assistance from the SCIC and from D. Recatalà with X-ray structures is acknowledged. Work at DPS laboratory was supported by grants from MINECO (SAF2009-11642 and SAF2012-36519), RD12/0013/0008 from ISCIII and CTS-6603 from Junta de Andalucía.

\section{Notes and references}

1 L. J. Ignarro, Nitric Oxide: Biology and Pathobiology, Academic Press, San Diego, 2010.

2 (a) T. Nagano and T. Yoshimura, Chem. Rev., 2002, 102, 1235; (b) M. Hetrick and M. H. Schoenfisch, Annu. Rev. Anal. Chem., 2009, 2, 409; (c) P. N. Coneski and M. H. Schoenfisch, Chem. Soc. Rev., 2012, 41, 3753.

3 (a) H. Kojima, Y. Urano, K. Kikuchi, T. Higuchi, Y. Hirata and T. Nagano, Angew. Chem., Int. Ed., 1999, 38, 3209; (b) H. Kojima, M. Hirotani, N. Nakatsubo, K. Kikuchi, Y. Urano, T. Higuchi, Y. Hirata and T. Nagano, Anal. Chem., 2001, 73, 1967; (c) E. Sasaki, H. Kojima, H. Nishimatsu, Y. Urano, K. Kikuchi, Y. Hirata and T. Nagano, J. Am. Chem. Soc., 2005, 127, 3684; (d) F. Galindo, N. Kabir, J. Gavrilovic and D. A. Russell, Photochem. Photobiol. Sci., 2008, 7, 126; (e) Y. Chen, W. Guo, Z. Ye, G. Wang and J. Yuan, Chem. Commun., 2011, 47, 6266; $(f)$ M. J. Marin, P. Thomas, V. Fabregat, S. V. Luis, D. A. Russell and F. Galindo, ChemBioChem, 2011, 12, 2471; $(g)$ L. Yuan, W. Lin, Y. Xie, B. Chen and J. Song, Chem. Commun., 2011, 47, 9372; (h) L. Yuan, W. Lin, Y. Xie, B. Chen and S. Zhu, J. Am. Chem. Soc., 2011, 134, 1305; (i) H. Yu, Y. Xiao and L. Jin, J. Am. Chem. Soc., 2012, 134, 17486; $(j)$ T. Terai, Y. Urano, S. Izumi, H. Kojima and T. Nagano, Chem. Commun., 2012, 48, 2840; (k) H. Yu, L. Jin, Y. Dai, H. Li and Y. Xiao, New J. Chem., 2013, 37, 1688.

4 (a) M. H. Sazinsky and S. J. Lippard, Acc. Chem. Res., 2006, 39, 558; (b) M. H. Lim, B. A. Wong, W. H. Pitcock, D. Mokshagundam, M.-H. Baik and S. J. Lippard, J. Am. Chem. Soc., 2006, 128, 14364; (c) M. D. Pluth, M. R. Chan, L. E. McQuade and S. J. Lippard, Inorg. Chem., 2011, 50, 9385; (d) B. Mondal, P. Kumar, P. Ghosh and A. Kalita, Chem. Commun., 2011, 47, 2964; (e) X. Hu, J. Wang, X. Zhu, D. Dong, X. Zhang, S. Wu and C. Duan, Chem. Commun., 2011, 47, 11507; $(f)$ U. P. Apfel, D. Buccella, J. J. Wilson and S. J. Lippard, Inorg. Chem., 2013, 52, 3285.

5 (a) Y. Yang, S. K. Seidlits, M. M. Adams, V. M. Lynch, C. E. Schmidt, E. V. Anslyn and J. B. Shear, J. Am. Chem. Soc., 2010, 132, 13114; (b) C. Sun, W. Shi, Y. Song, W. Chen and H. Ma, Chem. Commun., $2011,47,8638$.

6 X. Zhang, W. Kim, N. Hatcher, K. Potgieter, L. L. Moroz, R. Gillette and J. V. Sweedler, J. Biol. Chem., 2002, 277, 48472.

7 X. Ye, W.-S. Kim, S. S. Rubakhin and J. V. Sweedler, Analyst, 2004, $129,1200$.

8 W.-S. Kim, X. Ye, S. S. Rubakhin and J. V. Sweedler, Anal. Chem., 2006, 78, 1859.

9 X. Ye, S. S. Rubakhin and J. V. Sweedler, J. Neurosci. Methods, 2008, $168,373$.

10 (a) A. Katritzky, O. A. Schwarz, A. E. Abdel Rahman and D. E. Leahy, J. Heterocycl. Chem., 1984, 21, 1673; (b) D. Barton, N. Ozbalik and W. Sas, Tetrahedron, 1990, 46, 8043; (c) C. Reichardt, P. Milart and G. Schäfer, Liebigs Ann. Chem., 1990, 433.

11 IUPAC, Compendium of Chemical Terminology, 2nd edn (the "Gold Book”), Compiled by A. D. McNaught and A. Wilkinson, Blackwell Scientific Publications, Oxford, 1997, XML on-line corrected version: http://goldbook.iupac.org, 2006, created by M. Nic, J. Jirat, B. Kosata; updates compiled by A. Jenkins, ISBN 0-9678550-9-8.

12 A loss of $\mathrm{N}_{2}$ has also been described recently for another NO probe: T.-W. Shiue, Y.-H. Chen, C.-M. Wu, G. Singh, H.-Y. Chen, C.-H. Hung, W.-F. Liaw and Y.-M. Wang, Inorg. Chem., 2012, 51, 5400.

13 (a) M. Saura, D. Pérez-Sala, F. J. Cañada and S. Lamas, J. Biol. Chem., 1996, 271, 14290; (b) E. Cernuda-Morollón, F. Rodríguez-Pascual, P. Klatt, S. Lamas and D. Pérez-Sala, J. Am. Soc. Nephrol., 2002, 13, 2223. 